\title{
Glucagon-like peptide-1 enhances production of insulin in insulin-producing cells derived from mouse embryonic stem cells
}

\author{
L Bai, G Meredith and B E Tuch \\ Diabetes Transplant Unit, Prince of Wales Hospital and The University of New South Wales, Sydney, Australia \\ (Requests for offprints should be addressed to B Tuch, Diabetes Transplant Unit, Prince of Wales Hospital, High Street, Randwick NSW 2031, Australia; \\ Email: b.tuch@unsw.edu.au)
}

\begin{abstract}
Embryonic stem cells (ESCs) can be differentiated into insulin-producing cells by a five-stage procedure involving altering culture conditions and addition of nicotinamide. The amounts of insulin in these cells are lower than those found in pancreatic $\beta$ cells. Glucagon-like peptide-1 (GLP-1) induces the differentiation of $\beta$ cells from ductal progenitor cells. We examined the possibility of GLP-1, and its long-acting agonist exendin-4, enhancing the differentiation of insulin-producing cells from mouse ESCs (mESCs). A five-stage culturing strategy starting with embryoid bodies (EBs) was used in this study. mRNA for pancreatic duodenal homeobox gene 1 (PDX-1) and neurogenic differentiation (NeuroD) was detected from stage 1 , hepatocyte nuclear factor 3 beta (HNF3 $\beta$ ) and insulin 2 from stage $2, \mathrm{Ngn} 3$ and glucose transporter 2 (GLUT2) from stage 3, and insulin 1 and other $\beta$-cell markers, at stages $4-5$. Cells at stage 5 secreted C-peptide,
\end{abstract}

being $0.68 \pm 0.01 \mathrm{pmol} / 10^{6}$ cells per 2 days, and had an immunoreactive insulin content of $13.5 \pm 0.7 \mathrm{pmol} / 10^{6}$ cells. Addition of GLP-1 (100 nM) and nicotinamide $(10 \mathrm{mM})$ at stage 5 resulted in a $50 \%$ and $48 \%$ increase in insulin content and C-peptide secretion respectively compared with nicotinamide alone. Glucose-induced insulin secretion was enhanced 4-fold by addition of both growth factors. The GLP-1 receptor was present at all five stages of the culture. Addition of exendin-4 to cells at stage 2 resulted in a 4.9-fold increase in expression of the gene for insulin 1 and a 2-fold increase in insulin content compared with the effect of nicotinamide alone at stage 5 . It is concluded that both GLP-1 and exendin-4 enhance the level of expression of insulin in glucose-responsive insulinproducing cells derived from the R1 mESC line.

Journal of Endocrinology (2005) 186, 343-352

\section{Introduction}

Glucagon-like peptide-1 (GLP-1) is a peptide secreted from the gut in response to food. It acts directly on $\beta$ cells, enhancing the effect of glucose in stimulating insulin secretion from these cells. When administered to diabetic mice, GLP-1 lowers blood glucose levels and stimulates insulin secretion (Gutniak et al. 1992). In addition, GLP-1 increases the $\beta$-cell mass by inducing the differentiation and neogenesis of ductal progenitor cells into islet endocrine cells (Hui et al. 2001, Abraham et al. 2002). We have previously demonstrated that GLP-1 is capable of enhancing fetal pig $\beta$-cell differentiation from progenitor epithelial cells as well as initiating their functional maturation in islet-like cell clusters (ICCs) (Hardikar et al. 2002). Exendin-4, a long-acting GLP-1 receptor (GLP-1R) agonist, binds to and activates the GLP-1R with the same potency as GLP-1 (Xu et al. 1999). Exendin-4 is resistant to the enzyme dipeptidyl peptidase 4 (DPT-IV), which is present in serum. It has been reported previously that exendin-4 is capable of stimulating both the differentiation of $\beta$ cells from ductal progenitor cells and proliferation of $\beta$ cells when given to rats and human (Xu et al. 1999, Zhou et al. 1999, Stoffers et al. 2000, Habener 2001).

Embryonic stem cells (ESCs) are pluripotent and can be directed to differentiate along ectodermal, mesodermal and endodermal lineages to become different cell types. ESCs have been manipulated by using stringent culture conditions, or by the introduction of chimeric gene construct, into cells that synthesize and secrete insulin (Soria et al. 2000, Lumelsky et al. 2001, Hori et al. 2002, Blyszczuk et al. 2003). Manipulation of culture conditions in $\mathrm{mESCs}$ was employed in two of the studies (Lumelsky et al. 2001, Hori et al. 2002), which resulted in the production of a mixed population of endocrine cells including those that produced insulin, but at levels lower than those in pancreatic islets. However, another group (Rajagopal et al. 2003) has indicated that this may be due to an artifact caused by the presence of insulin in unconditioned culture medium.

In the present study, we examined the possibility of GLP-1 and its long-acting agonist, exendin-4, enhancing the differentiation of insulin-producing cells from mESCs. 


\section{Materials and Methods}

\section{Reagents}

Culture medium knockout Dulbecco's modified Eagle's medium (KO DMEM), L-glutamine, $\beta$-mercaptoethanol, penicillin-streptomycin, fetal bovine serum (FBS), nonessential amino acids (NEAAs), B27 serum-free supplement, $\mathrm{N}_{2}$ serum-free supplement, mouse basic fibroblast growth factor (bFGF), insulin-transferrin-selenium (ITS) solution were obtained from Gibco. Gelatin, fibronectin, transferrin, nicotinamide and chloroform were from Sigma while ESGRO leukaemia inhibitory factor (LIF) and exendin-4 were from the American Peptide Company (Sunnyvale, CA, USA). TRIZOL reagent, ethidium bromide, agarose, DNase 1 Amplification Grade Kit, SuperScript III First Strand Synthesis System Kit and Platinum Taq DNA Polymerase Kit were from Invitrogen. The Red Hot DNA Polymerase Kit was from ABgene (Epsom, Surrey, UK). The AmpliTaq Gold Kit was from Roche. Isopropyl alcohol was obtained from Merck and absolute ethanol was from Yarraville Distillery (Yarraville, Victoria, Australia). The labelled streptavidin-biotin (LSAB) 2 Horse Radish Peroxidase (HRP) Kit, amino-ethylcarbazole (AEC) substrate chromogen and haematoxylin, polyclonal guinea pig anti-human insulin and rabbit antiguinea pig immunoglobulin $\mathrm{G}$ ( $\mathrm{IgG}$ ) were obtained from DAKO (Carpintaria, CA, USA). The polyclonal rabbit anti-human GLP-1R antibody was received as a gift from Dr Daniel Drucker of The Banting and Best Diabetes Centre, University of Toronto, Canada.

\section{Cell culture}

Undifferentiated mESCs, from the -R1 cell line (Nagy et al.1993) kindly supplied by Dr Patrick Tam from the Children's Medical Research Institute at Westmead, Sydney, were cultured on a feeder layer of irradiated mouse embryonic fibroblasts with medium containing KO DMEM, penicillin-streptomycin, $100 \mu \mathrm{M} \beta$-mercaptoethanol, $2 \mathrm{mM}$ L-glutamine, $100 \mathrm{nM}$ NEAA, 10\% FBS and $1000 \mathrm{U} / \mathrm{ml}$ LIF. Medium was changed daily, and cells were split every 2-3 days.

To convert mESCs into insulin-producing cells, a five-stage culture strategy was used in the absence of a feeder layer. The strategy is a modification of that previously described (Lumelsky et al. 2001). Stage 1: mESCs were cultured on a gelatin-coated culture surface without a feeder layer but in the ES medium as described before for 2-3 days to expand the cells in an undifferentiated state. Stage 2: mESCs were harvested and then cultured in suspension for 3 days in the ES medium without LIF to generate embryoid bodies (EBs). Stage 3: EBs were transferred to culture dishes and allow to adhere overnight, then cultured for 6 days in serum-free medium supplemented with ITS solution, with final concentrations of
$10 \mathrm{mg} / 1$ insulin, $56 \mathrm{mg} / 1$ transferrin, $6.7 \mathrm{mg} / 1$ selenium and $5 \mathrm{mg} / 1$ fibronectin, to select a specific cell population, thought to be nestin-positive cells. Stage 4: cells were transferred to geletin-coated plates and cultured for 6 days in the presence of the mitogen bFGF $10 \mathrm{ng} / \mathrm{ml}$, in $\mathrm{N}_{2}$ serum-free medium containing B27 medium supplement, to expand the pancreatic progenitor cells. Stage 5: cells were cultured for 6 days in $\mathrm{N}_{2}$ medium plus B27 supplement. In order to induce the differentiation of cells into insulin-producing cells, $10 \mathrm{mM}$ nicotinamide and 100 nM GLP-1/10 nM exendin-4 were added. These concentrations of agents were selected based on maximal effects observed with them in differentiation of fetal pancreatic tissue (Hardikar et al. 2002, authors' unpublished observations).

\section{Insulin content}

Iinsulin was extracted from cells of each stage by incubating overnight with acid-ethanol at $4{ }^{\circ} \mathrm{C}$. Immunoreactive insulin content was measured by RIA using a rat insulin standard; the lower limit of sensitivity of the assay was $0 \cdot 25 \mathrm{ng} / \mathrm{ml}$. Cross-reactivity with proinsulin was $73 \%$.

\section{C-peptide}

To measure C-peptide release, the culture medium from each stage was collected and stored at $-80{ }^{\circ} \mathrm{C}$. The medium was concentrated by freeze drying and the amount of C-peptide in the culture medium was then measured by RIA using a rat C-peptide RIA kit (Linco, MO, USA); the lower limit of sensitivity of the assay was 25 pM. Rat insulin is not detected in the assay; crossreactivity with human proinsulin is $<0 \cdot 01 \%$, but crossreactivity with mouse proinsulin is unknown.

\section{Insulin secretion}

For static incubation, cells from stage 5 were plated in 12-well culture plates at a density of 500000 cells per well, allowed to attach to the bottom of the well and proliferate overnight. Cells were then washed thoroughly with basal medium (PBS containing $1 \mathrm{mM} \mathrm{CaCl}$, $20 \mathrm{mM}$ Hepes, $2 \mathrm{mg} / \mathrm{ml} \mathrm{BSA}$ and $2.8 \mathrm{mM}$ glucose) to remove culture medium. Monolayers were incubated in the basal medium for two consecutive $1-\mathrm{h}$ periods to stabilize the basal secretion of insulin. Monolayers were then exposed to $20 \mathrm{mM}$ glucose for $1 \mathrm{~h}$. The medium was then collected, and its immunoreactive insulin content measured by RIA using a rat insulin standard.

\section{$R T-P C R$}

Total RNA was isolated from undifferentiated ES cells and the cells from stages 1 to 5 using TRIzol reagent and followed by DNase treatment; $1 \mu \mathrm{g}$ total RNA from each 
Table 1 Primer sequences and PCR product size

\begin{tabular}{|c|c|c|c|}
\hline \multirow[b]{2}{*}{ Gene } & \multirow[t]{2}{*}{ Forward primer } & \multirow[t]{2}{*}{ Reverse primer } & \multirow[t]{2}{*}{ Product (bp) } \\
\hline & & & \\
\hline GLP-1R & tcagagacggtgcagaaatg & cagctgacattcacgaagga & 158 \\
\hline Oct-4 & ggcgttctctttggaaaggtgttc & ctcgaaccacatccttctct & 312 \\
\hline AFP & acaggaggctatgcatcacc & tggacatcttcaccatgtgg & 470 \\
\hline BMP-4 & tgtgaggagtttccatcacg & ttattcttcttcctggaccg & 566 \\
\hline Nestin & caagaaccactggggtctgt & tcccacctctgttgacttcc & 248 \\
\hline PDX-1 & tgtaggcagtacgggtcctc & ccaccccagtttacaagctc & 325 \\
\hline NeuroD & cttggccaagaactacatctgg & cgtgtttgaaagagaagttgcc & 430 \\
\hline Nkx6·1 & tcagtcaaggtctggttcc & cgatttgtgctttttcagca & 211 \\
\hline Ngn3 & aagagcgagttggcactgagc & aagctgtggtccgctatgcg & 223 \\
\hline GK & ggaacaacatcgtgggactt & tgaaggtgatttcgcacttg & 783 \\
\hline Glut2 & ggataaattcgcctggatga & ttcctttggtttctggaact & 298 \\
\hline PC1 & ttggctgaaagggaaagaga & gcttcatgtgctctggttga & 202 \\
\hline PC2 & ctgtgacggctatgcttcaa & agctgcagatgtcccagagt & 205 \\
\hline Insulin I & atggccctgttggtgcacttcc & ttagttgcagtagttctccagctgg & 320 \\
\hline Insulin 2 & ccetgctggecetgctctt & aggtctgaaggtcacctgct & 212 \\
\hline PP & ctgcetctccetgtttctc & ggctgaagacaagagaggc & 337 \\
\hline SS & gtttctgcagaagtctctgg & agttcttgcagccagctttg & 187 \\
\hline CK19 & gtgccaccattgacaactcc & aatccacctccacactgacc & 268 \\
\hline Amylase & cattgttgcaccttgtcacc & ttctgctgctttccctcatt & 300 \\
\hline Carboxypeptidase A & gcaaatgtgtgtttgatgcc & atgaccaaactcttggaccg & 521 \\
\hline GAPDH & aatcccatcaccatcttcca & ggcagtgatggcatggactg & 336 \\
\hline
\end{tabular}

GLP-1R, glucagon-like peptide-1 receptor; Oct-4, Octamer-binding transcription factor 4; AFP, alpha fetoprotein; BMP-4, bone morphogenic protein-4; PDX-1, pancreatic duodenal homeobox gene 1; NeuroD, neurogenic differentiation; NKx6·1, NK6 transcription factor related, locus 1; Ngn3, neurogenin 3; GK, glucokinase; GLUT2, glucose transporter 2; PC1 \& 2, prohormone convertase $1 \&$ 2; PP, pancreatic polypeptide; SS, somatostatin; CK19, cytokeratin 19; GAPDH, glyceraldehyde-3-phosphate dehydrogenase.

sample was then used to prepare single-stranded cDNA with the SuperScript First-Strand System for RT-PCR. A standard $25 \mu \mathrm{PCR}$ reaction was performed in a thermal cycle using the following profile: an initial denaturation step at $95^{\circ} \mathrm{C}$ for $2 \mathrm{~min}$, followed by 35 cycles of denaturation at $95{ }^{\circ} \mathrm{C}$ for $45 \mathrm{~s}$, annealing at $52-62{ }^{\circ} \mathrm{C}$ for $45 \mathrm{~s}$ (depending on the primer) and elongation at $72{ }^{\circ} \mathrm{C}$ for $60 \mathrm{~s}$. The samples were finally incubated at $72{ }^{\circ} \mathrm{C}$ for 5 min. PCR products were separated on a $1 \%$ TAE agarose gel, photographed and analysed using the Gel Doc 1000 system (BioRad). Quantification of the blots and comparison with the housekeeping gene was performed with software ImageJ, with experiments being repeated 3-4 times for each gene. The primer sequences used for PCR are shown in Table 1.

\section{Immunohistochemistry}

Immunohistochemistry was performed on paraffin sections of cultured mESCs. After dewaxing and serial alcohol rehydration, the sections were exposed to $3 \% \mathrm{H}_{2} \mathrm{O}_{2}$ to remove endogenous peroxidase, and 1\% BSA to block non-specific binding. The sections were then incubated overnight with primary antibodies, anti-human GLP-1R polyclonal antibody at 1:1000. The next morning, the slides were washed with PBS, exposed to biotinylated anti-rabbit/mouse for $15 \mathrm{~min}$ and then incubated with streptavidin-peroxidase conjugate for a further $15 \mathrm{~min}$. Finally, the sections were treated with substratechromogen AEC. A standard concentration of haematoxylin $(0 \cdot 1 \%)$ was added as a counterstain. The primary antibody was omitted for the negative control.

\section{Statistics}

Data were analysed by Student's $t$-test when there were two groups to be compared, and by analysis of variance and Duncan's test when there were more than two groups. The statistical package used was Number Cruncher Statistical Systems (Kaysville, UT, USA).

\section{Results}

\section{Insulin and C-peptide production}

Intracellular immunoreactive insulin content was detected at stage 3 with a significant increase at stage 5 (Fig. 1A). Addition of GLP-1 at stage 5 resulted in a $50 \%$ increase in immunoreactive insulin content compared with the addition of nicotinamide alone $\left(20 \cdot 1 \pm 3 \mathrm{pmol} / 10^{6}\right.$ cells vs $13 \cdot 5 \pm 0 \cdot 7 \mathrm{pmol} / 10^{6}$ cells).

Immunoreactive C-peptide was also produced from the cells at stage 5 , which probably indicates their ability to 


\section{Insulin content}

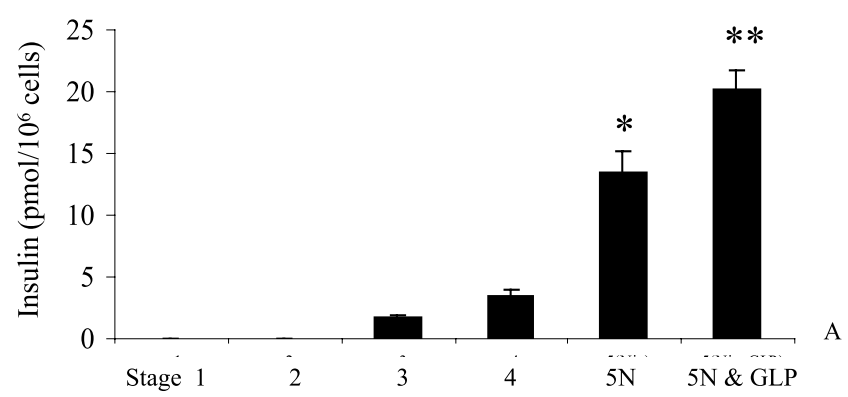

\section{C-peptide secretion}

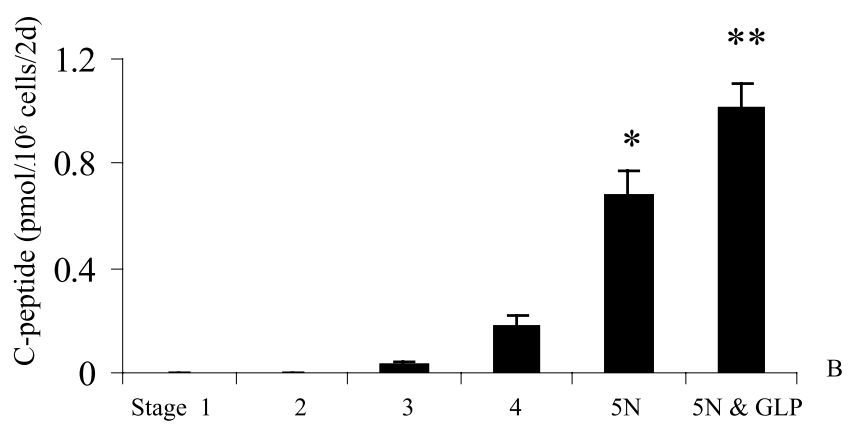

Figure 1 Immunoreactive insulin content (A) and C-peptide secretion (B) for mESCs at different stages of culture. The number of samples was 12 (4 replicates in 3 separate experiments). ${ }^{*}$ Stage $5 \mathrm{~N}$ \& GLP>* stage $5 \mathrm{~N}>$ stages 3 and $4 ; P<0 \cdot 05$. Abbreviations: $5 \mathrm{~N}$, stage 5 cells with nicotinamide; $5 \mathrm{~N} \& \mathrm{GLP}$, stage 5 cells with nicotinamide and GLP-1.

cleave proinsulin in the same manner as a pancreatic $\beta$ cell. An alternative explanation is that the cells were producing proinsulin (but not insulin) since the cross-reactivity of mouse proinsulin in the assay is unknown. This explanation seems unlikely since the RIA used detects neither insulin (rodent or human) nor human proinsulin. The addition of GLP-1 to stage 5 cells resulted in a $48 \%$ increase in C-peptide release $\left(1 \cdot 01 \pm 0 \cdot 01 \mathrm{pmol} / 10^{6}\right.$ cells vs $0.68 \pm 0 \cdot 01 \mathrm{pmol} / 10^{6}$ cells) (Fig. 1B). Insulin secretion expressed as a percentage of content was $5 \%$.

Finally, stage 5 cells, or mES-derived insulin-producing cells, secreted immunoreactive insulin in response to $20 \mathrm{mM}$ glucose. There was a $2 \cdot 2-$ and $4 \cdot 4$-fold increase in insulin secretion in the presence of nicotinamide alone and nicotinamide + GLP-1 respectively. Levels of immunoreactive insulin increased from $2.25 \pm 0.95$ to 4.99 $\pm 1.89 \mathrm{ng} / 10^{6}$ cells per hour for the nicotinamide group $(n=6)$ and from $1 \cdot 74 \pm 0 \cdot 34$ to $7 \cdot 68 \pm 1 \cdot 4 \mathrm{ng} / 10^{6}$ cells per hour for the nicotinamide + GLP-1 group $(n=6)$.

\section{Effect of GLP-1 on mESC differentiation}

The effect of GLP-1 on the differentiation of cells into insulin-producing cells was determined by analysis of gene expression. The transcription factor Oct-4, a marker of ESC pluripotency, was down-regulated at the late stages of cell development and absent at stage 5 (Fig. 2). Three germ line markers, $\alpha$-fetoprotein (AFP) (endodermal marker), nestin (ectodermal marker) and bone morphogenic protein-4 (BMP-4) (mesodermal marker) were also analysed within this modified differentiation protocol. All three lineage markers were present from stage 1 (Fig. 2). The expression of the endodermal marker AFP and ectodermal marker nestin were significantly up-regulated in cells of stage 2 (Fig. 2B); with no difference in the presence of nicotinamide alone and both nicotinamide and GLP-1. The expression of the mesodermal marker BMP-4 was down-regulated in cells of stage 5 , particularly in the presence of GLP-1.

\section{Expression of genes of $\beta$-cell development during the differentiation process}

The transcription factors PDX-1, NKx6 1 , NeuroD and Ngn3 (known to be involved in pancreatic $\beta$-cell development in vivo), and HNF3 $\beta$ (a transcription factor involved in endodermal development) were analysed by RT-PCR. 


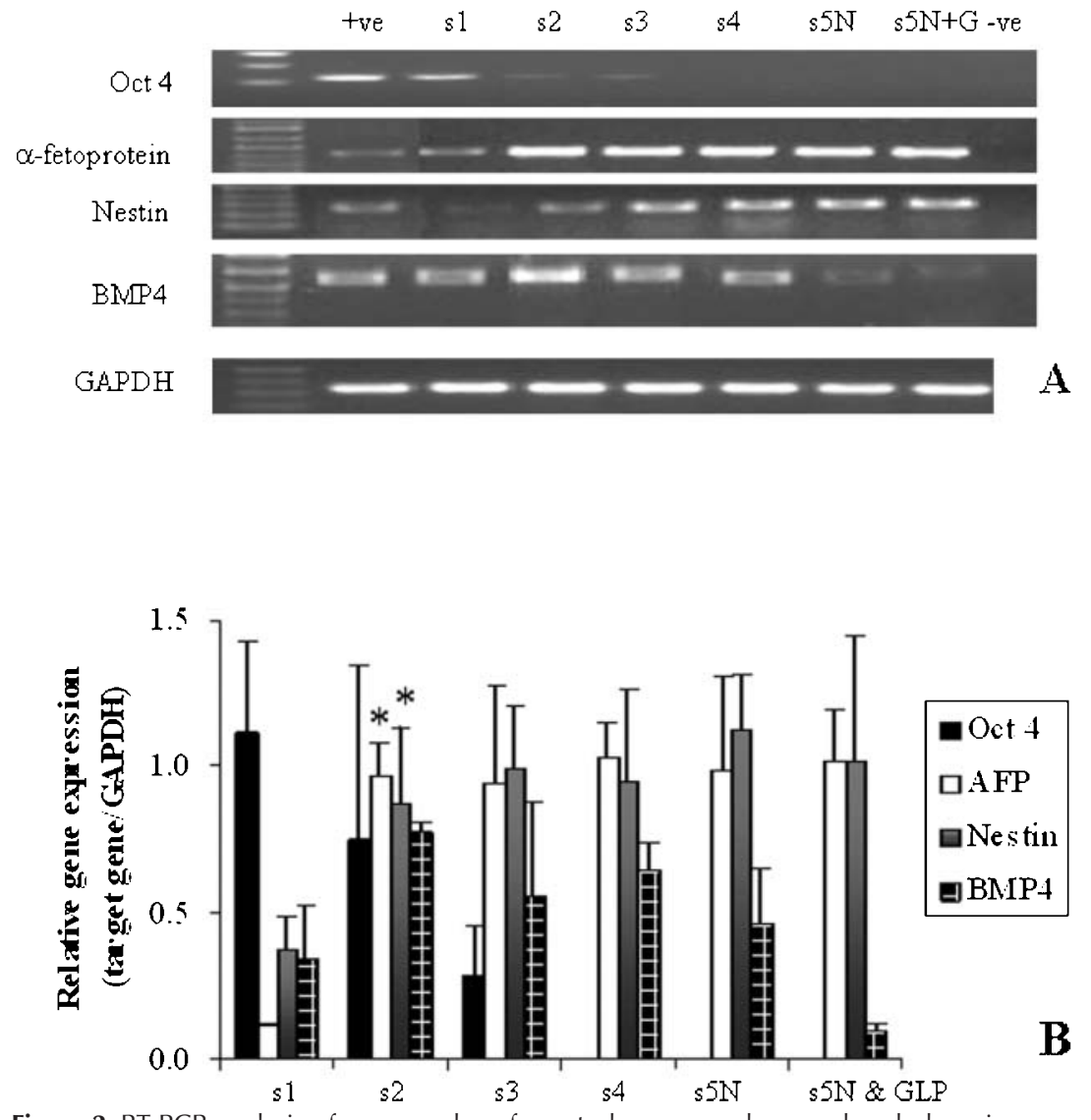

Figure 2 RT-PCR analysis of gene markers for ectoderm, mesoderm and endoderm in differentiating mESCs. (A) Abbreviations: s1, stage 1 cells; s2, stage 2 cells; s3, stage 3 cells; s4, stage 4 cells; s5N, stage 5 cells with nicotinamide; s5N+G, stage 5 cells with nicotinamide and GLP-1. In order to show results clearly, the figure has been put together with gels carried out at different times. (B) Quantification of gene expression relative to the housekeeping gene GAPDH; $n=3-4$ for each gene; ${ }^{*} P<0 \cdot 0001$ for stage 2 vs stage 1 . AFP, $\alpha$-fetoprotein; BMP-4, bone morphogenic protein- 4 .

PDX-1 was present in all five stages of development with slightly elevated levels at stage 5 (Fig. 3). HNF3 $\beta$ was present from stage 2, Nkx6.1 and NeuroD from stage 3, and Ngn3 from stage 3 (Fig. 3).

\section{Expression of mature pancreatic cell markers during the} differentiation process

Several genes expressed in mature pancreatic $\beta$ cells were analysed during the differentiation process (Fig. 4). Insulin 1 was present only at stage 5 while insulin 2 was present from stage 2 at a time when culture medium was not supplemented with insulin, and increased significantly thereafter (Fig. 4B). Glucagon was present only at stage 5, somatostatin from stage 3 , but pancreatic polypeptide was undetectable at all five stages. Glucokinase, a $\beta$-cell marker, was present at stage 5 and glucose transporter 2 (GLUT2) from stage 3. PC1 and PC2, key enzymes involved in the cleavage of proinsulin to insulin and C-peptide, were present from stage 4 with higher levels at stage 5 .

\section{Identification of the GLP-1R}

RT-PCR and immunohistochemistry were used to determine the stage-specific expression of the GLP-1R during the differentiation of mESCs. GLP-1R gene was expressed in all stages of the differentiation protocol (Fig. 5A). The level of expression was similar in all stages throughout the differentiation process. A positive control was achieved by using cDNA from an insulinoma cell line NIT-1, and a sample negative control achieved by using adult mouse skeletal muscle cDNA. A water negative control was used to ensure there was no contamination of the PCR components.

Immunohistochemical staining confirmed the result. Cells of all stages were stained positively for the 


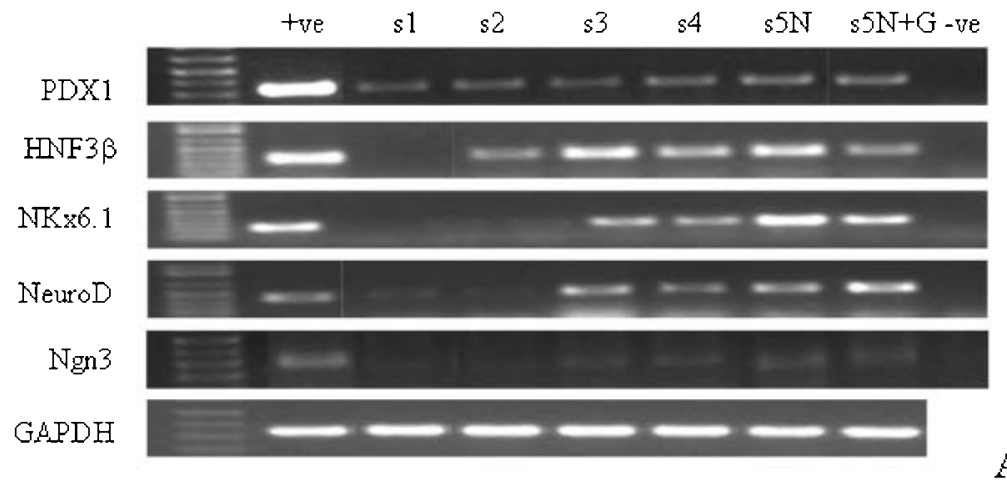

A

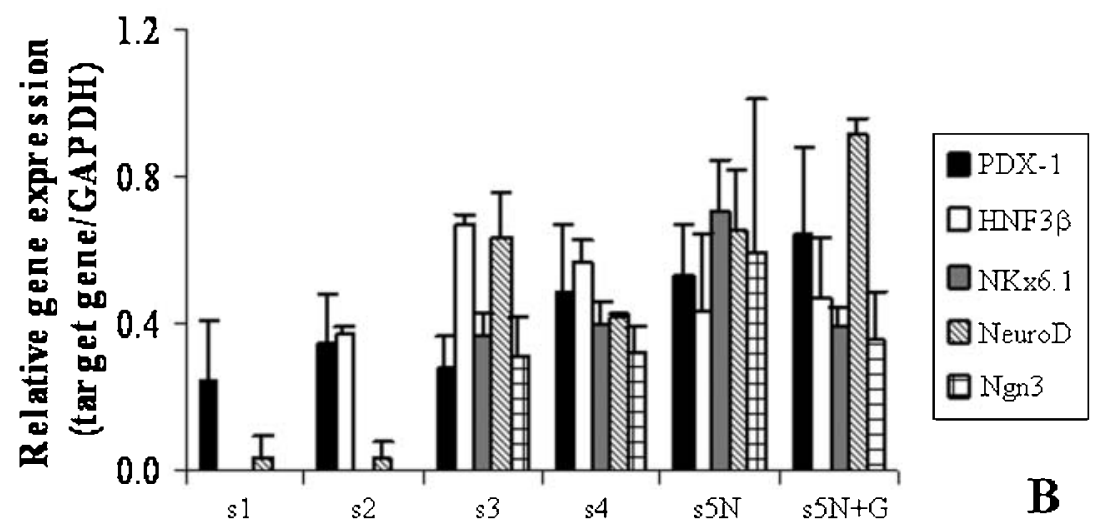

Figure 3 Expression of pancreatic transcription factors in differentiating ESCs. (A)

Abbreviations as in Fig. 2 caption. In order to show results clearly, the figure has been put together with gels carried out at different times. (B) Quantification of gene expression relative to the housekeeping gene $\mathrm{GAPDH} ; n=3-4$ for each gene.

GLP-1R (Fig. 5B). The staining was localized within the cytosol and the plasma membrane of positively staining cells. Semi-quantitatively, the percentage of positive staining cells of all five stages was similar (80\%). Adult mouse pancreas was used as a positive control, while adult mouse testis was used as a sample negative control.

\section{Effect of exendin-4 on mESC differentiation}

Due to the expression of the GLP-1R at all stages, exendin-4, a long-acting agonist of the GLP-1R, was added to the culture media at stages 2 to 5 . Addition of exendin-4 at the early stage resulted in a significant $4 \cdot 9$-fold increase in expression of insulin 1 compared with the addition of nicotinamide alone at stage $5(P=0 \cdot 026)$. However, there was no significant difference in expression compared with that observed when both nicotinamide and exendin-4 were added at stage 5 (Fig. 6A and B). Expression of the gene for insulin 2 in all three groups was not significantly different.
As might be expected, the immunoreactive insulin content of stage 5 ESCs was enhanced, 2-fold, when exendin-4 was added from stage 2 as compared with addition of nicotinamide alone at stage 5 (Fig. 6C).

\section{Discussion}

Recent studies have shown that mESCs can differentiate into insulin-producing cells and form structures that resemble those of pancreatic islets by varying the culture conditions (Lumelsky et al. 2001, Hori et al. 2002). The insulin-producing capacity of these cells has been questioned due to findings of Rajagopal et al. (2003), which indicated that insulin immunoreactivity was an artifact caused by insulin uptake from the culture medium. In addition, recent findings have suggested that insulinproducing cells derived from Lumelsky's protocol are not $\beta$ cells but cells that have neuronal characteristics (Sipione et al. 2004). Our studies showed that using a modification 


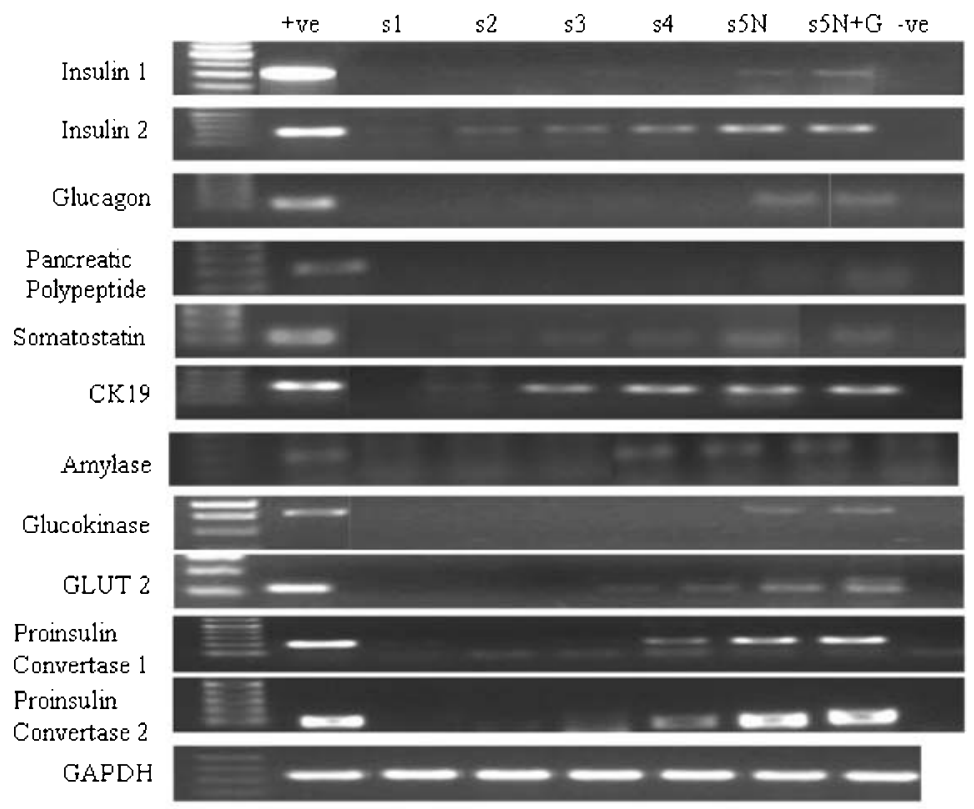

$\mathbf{A}$

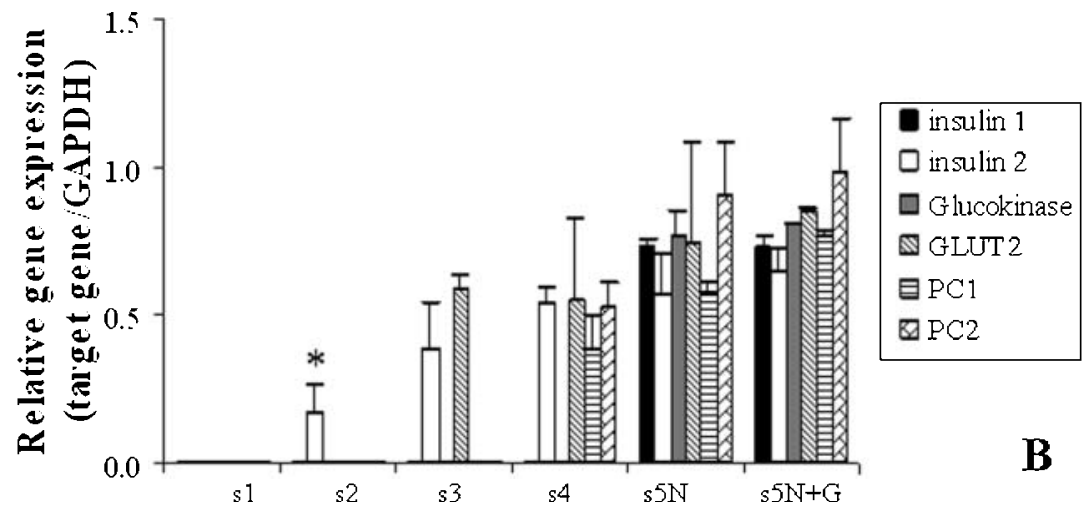

Figure 4 RT-PCR analysis of mature pancreatic cell markers in differentiating ESCs. (A) Abbreviations as in Fig. 2 caption. In order to show results clearly, the figure has been put together with gels carried out at different times. (B) Quantification of gene expression relative to the housekeeping gene GAPDH; $n=3-4$ for each gene; ${ }^{*} P=0.003$ for stage $2 \mathrm{vs}$ stages $3-5$.

of a five-stage method described by Lumelsky, mESCs were converted into insulin-producing cells. These cells secreted immunoreactive insulin in response to glucose, along with C-peptide, indicating that the immunoreactive insulin was being produced by the cells rather than being taken up from the culture media. Also, we found both insulin 1 and 2 mRNA expressed in the cells, with insulin 2 being expressed in cells at stage 2, when the medium is not supplemented with insulin. This is in contrast to the data from others, who detected no insulin transcripts (Rajagopal et al. 2003) or only insulin 2 (Sipione et al. 2004). While the expression of genes for the transcription factors PDX-1 and Ngn3 that we found in the developing cells is not exclusive to pancreatic precursors and is present during neuronal development (Sommer et al. 1996, PerezVillamil et al. 1999), at least some of the cells produced at the later stages of culture were of pancreatic origin. The cells expressed genes found in pancreatic exocrine and duct cells, all four pancreatic endocrine cells $(\alpha, \beta, \delta$ and $\mathrm{PP})$, as well as a number of genes found in pancreatic $\beta$ cells (namely glucokinase, GLUT2, PC1 and PC2). The difference between our results and those of Sipione et al. (2004), whose insulin-producing cells were glucose unresponsive, and did not express insulin 1 and rarely glucagon, 
GLP-1R
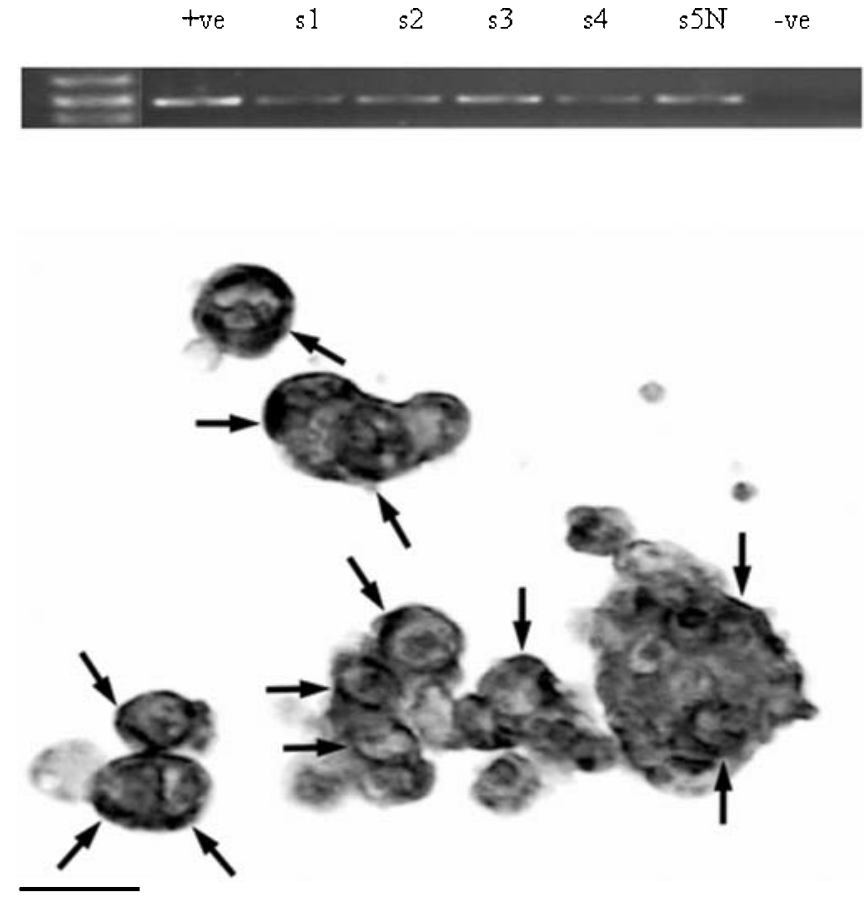

B

Figure 5 Expression of receptor for GLP-1 in differentiating ESCs. (A) RT-PCR analysis of GLP-1R gene expression in all stages of differentiating ESCs. Abbreviations as in Fig. 2 caption. (B) ESCs at stage 1 stained with GLP-1R antibody. The receptor is identified as a dark stain on the surface of cells (arrows). Scale bar, $50 \mu \mathrm{m}$.

may be due to the different mESC lines examined. Although the cells were able to produce immunoreactive insulin, the production of this hormone from the cells, $0.5 \mathrm{pmol} / 10^{6}$ cells per day, was much lower than that from pancreatic $\beta$ cells, $0 \cdot 14 \mathrm{pmol} /$ islet per day (Tuch et al. 1989), or $140 \mathrm{pmol} / 10^{6}$ cells per day if it is assumed that there are 1000 cells in an islet. Also, the cell population was not homogenous. When transplanted into NOD/SCID mice, all mice developed teratomas (data not shown), which display features of tissues arising from three germ layers.

The novel strategy of our approach was the addition of a gut hormone, GLP-1, and its receptor agonist exendin-4, to enhance mESC differentiation. Previously, we had demonstrated that GLP-1 promoted the differentiation of $\beta$ cells from fetal pancreatic precursor cells (Hardikar et al. 2002). In the current experiments we have demonstrated that addition of GLP-1 as well as nicotinamide at stage 5 of the differentiation protocol resulted in a $50 \%$ increase in immunoreactive insulin content compared with nicotinamide alone. The increase in intracellular immunoreactive insulin was associated with an increase in secretion of C-peptide from the cell. The down-regulation of the mesodermal marker BMP-4 indicates that GLP-1 was exerting an effect on cell differentiation; however it is possible that the hormone was increasing the number of insulin-producing cells by enhancing their proliferation and/or increasing the insulin production per cell. It is not possible to distinguish which of these three explanations was predominant, since immunoreactive insulin producing cells in stage 5 could not readily be identified histologically. The cells did not stain for C-peptide (DAKO anti-rodent antibody). It is also possible that the effect of GLP-1 was being exerted on only a fraction of the stage 5 cells. Glucose-induced insulin secretion, following addition of both growth factors, was enhanced 4-fold compared with a 2-fold increase when treated with nicotinamide alone. This effect might be due to a direct effect of GLP-1, an effect observed on pancreatic $\beta$ cells.

Due to the favourable effects of GLP-1 on differentiating mESCs, we sought the GLP-1R at different stages of culture in order to determine the earliest time it would be logical to introduce this hormone or its long-acting agonist, exendin-4. Surprisingly GLP-1R mRNA was detected at all stages of culture and even in mESCs cultured on feeder layer (results not shown), indicating that the removal of the feeder layer was not a contributing factor determining its presence. This finding was confirmed using immunohistochemistry. The presence of the GLP-1R in undifferentiated mESCs may be a result of several factors. Firstly, pluripotent cells in vivo may express the GLP-1R. To date, no study has identified the 


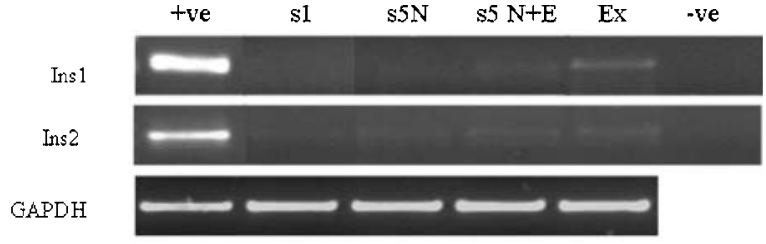

A

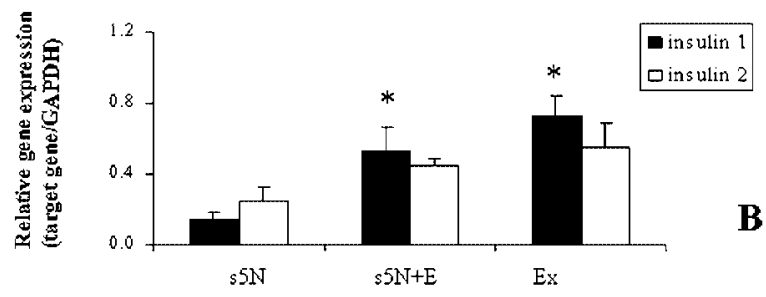

Insulin content

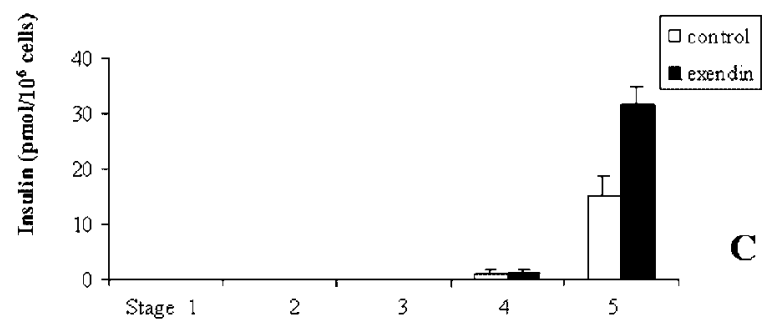

Figure 6 Effect of exendin-4 on differentiation of mESCs. Exendin-4 was added from stage 2. (A) Insulin 1 and 2 expression in differentiating mESCs. (B) Quantification of gene expression relative to the housekeeping gene $\mathrm{GAPDH} ; n=3-4$ for each gene. (C) Insulin content of differentiating mESCs. Abbreviations: Ex, adding exendin- 4 from stage 2 of differentiation of ESCs; $s 5 N+E$, adding exendin- 4 and nicotinamide at stage $5 ; \mathrm{s} 5 \mathrm{~N}$, adding nicotinamide at stage $5 .{ }^{*}, P<0 \cdot 05$ for $\mathrm{s} 5 \mathrm{~N}+\mathrm{E}$ and Ex vs $\mathrm{s} 5 \mathrm{~N}$.

GLP-1R within the ICM of the developing blastocyst. Even if present, studies conducted by Scrocchi et al. (1998) have indicated that GLP-1R null mice are viable and reproduce normally, indicating a lack of function in the development of the embryo. Secondly, ESCs have been shown to express many otherwise tissue-specific genes with no apparent role (Friedrich \& Soriano 1991). This in vitro characteristic of the differentiating ESCs may result in 'background' expression of genes not specific to the functional ESC. Thirdly, the presence of the GLP-1R may be a result of mESCs that have spontaneously differentiated into cells that characteristically express the GLP-1R gene. Due to the high percentage of stage 1 cells staining positively for the GLP-1R it is probable that its presence is characteristic of in vitro mESCs and not from cells that have spontaneously differentiated. Also of interest, stage 2 GLP-1R-positive cells were found predominantly in the single columnar layer lining the EBs. This layer of cells is of an endodermal lineage, expressing a number of endodermal markers including AFP and HNF-3 $\beta$ (Abe et al. 1996, Karbanova \& Mokry 2002). Since the GLP-1R was present at all stages of cell development, we added a GLP-1 agonist (exendin-4) to cells as they started to differentiate (stage 2). As expected, this had a beneficial effect, with enhanced expression of the insulin 1 gene and immunoreactive insulin content.

In conclusion, we have demonstrated that mESCs can be converted into immunoreactive insulin-producing cells by varying the culture conditions. GLP-1 and exendin4 have beneficial effects on the production of immunoreactive insulin from mESC. However, the levels produced are lower than those produced by pancreatic $\beta$ cells, and the cell population is not homogenous, so that it is not suitable for transplantation as a therapy for diabetes.

\section{Acknowledgements}

We wish to thank the Sydney Foundation for Medical Research and the Rebecca Cooper Medical Research Foundation for financial support. The authors declare that there is no conflict of interest that would prejudice the impartiality of this scientific work.

\section{References}

Abe K, Niwa H, Iwase K, Takiguchi M, Mori M, Abe SI, Abe K \& Yamamura KI 1996 Endoderm-specific gene expression in embryonic stem cells differentiated to embryoid bodies. Experimental Cell Research 229 27-34.

Abraham EJ, Leech CA, Lin JC, Zulewski H \& Habener JF 2002 Insulinotropic hormone glucagon-like peptide-1 differentiation of human pancreatic islet-derived progenitor cells into insulinproducing cells. Endocrinology 143 3152-3161.

Blyszczuk P, Czyz J, Kania G, Wagner M, Roll U, St-Onge L \& Wobus AM 2003 Expression of Pax4 in embryonic stem cells promotes differentiation of nestin-positive progenitor and insulin-producing cells. PNAS 100 998-1003.

Friedrich G \& Soriano P 1991 Promoter traps in embryonic stem cells: a genetic screen to identify and mutate developmental genes in mice. Genes and Development 5 1513-1523.

Gutniak M, Orskov C, Holst JJ, Ahren B \& Efendic S 1992 Antidiabetogenic effect of glucagon-like peptide1 (7-36) amide in normal subjects and patients with diabetes mellitus. New England Journal of Medicine 326 1316-1322.

Habener JF 2001 Glucagon-like peptide 1 agonist stimulation of $\beta$-cell growth and differentiation. Current Opinion in Endocrinology and Diabetes 8 74-81.

Hardikar AA, Wang XY, Williams L, Kwok J, Wong R, Yao M \& Tuch BE 2002 Functional maturation of fetal porcine beta cells by glucagon-like peptide 1 and cholecystokinin. Endocrinology 143 3505-3514.

Hori Y, Rulifson IC, Tsai BC, Heit JJ, Cahoy JD \& Kim SK 2002 Growth inhibitors promote differentiation of insulin-producing tissue from embryonic stem cells. PNAS 99 16105-16110.

Hui R, Wright C \& Perfetti R 2001 Glucagon-like peptide 1 induces differentiation of islet duodenal homeobox-1 positive pancreatic ductal cells into insulin-secretion cells. Diabetes 50 785-796.

Karbanova J \& Mokry J 2002 Histological and histochemical analysis of embryoid bodies. Acta Histochemica 104 361-365. 
Lumelsky N, Blondel O, Laeng P, Velasco I, Ravin R \& Mckay R 2001 Differentiation of embryonic stem cells to insulin-secreting structure similar to pancreatic islets. Science 292 1389-1394.

Nagy A, Rossant J, Nagy R, Abramow-Newerly W \& Roder JC 1993 Derivation of completely cell culture-derived mice from early-passage embryonic stem cells. PNAS 90 8424-8428.

Perez-Villamil B, Schwarz PT \& Vallejo M 1999 The pancreatic homeodomain transcript factor IDX/IPF1 is expressed in neural cells during brain development. Endocrinology 140 3857-3860.

Rajagopal J, Anderson WJ, Kume S, Martinez OI \& Melton DA 2003 Insulin staining of ES cell progeny from insulin uptake. Science 299 324.

Scrocchi LA, Marshall BA, Cook SM, Brubaker PL \& Drucker DJ 1998 Identification of glucagon-like peptide 1 (GLP-1) actions essential for glucose homeostasis in mice with disruption of GLP-1 receptor signalling. Diabetes $\mathbf{4 7}$ 632-639.

Sipione S, Eshpeter A, Lyon J, Korbutt G \& Bleackley R 2004 Insulin expression cells from differentiated embryonic stem cells are not beta cells. Diabetologia 47 499-508.

Sommer L, Ma Q \& Anderson DJ 1996 Neurogenins, a novel family of atonal-related bHLH transcription factors, are putative mammalian neuronal determination genes that reveal progenitor cell heterogeneity in the developing CNS and PNS. Molecular and Cellular Neurosciences 8 221-241.

Soria B, Roche E, Berna G, Leon-Quinto T, Reig JA \& Matin F 2000 Insulin-secreting cells derived from embryonic stem cells normalize glycemia in streptozotocin-induced diabetic mice. Diabetes 49 157-162.

Stoffers DA, Kieffer TJ, Hussain MA, Drucker DJ, Bonner-Weir S, Habener JF \& Egan JM 2000 Insulinotropic glucagon-like peptide 1 agonists stimulate expression of homeodomain protein IDX-1 and increase islet size in mouse pancreas. Diabetes 49 741-748.

Tuch BE, Turtle JR \& Simeonovic CJ 1989 Streptozotocin is not toxic to the human fetal beta cell. Diabetologia 32 678-684.

Xu G, Stoffers DA, Habener JF \& Bonner-Weir S 1999 Exendin-4 stimulates both $\beta$-cell replication and neogenesis, resulting in increased $\beta$-cell mass and improved glucose tolerance in diabetic rats. Diabetes 48 2270-2276.

Zhou J, Wang Y, Pineyro MA \& Egan JM 1999 Glucagon-like peptide 1 and exendin-4 convert pancreatic AR42J cells into glucagon- and insulin-producing cells. Diabetes 48 2358-2366.

Received in final form 24 May 2005

Accepted 7 April 2005 